\title{
Pengendalian Produk Cacat Piece Pivot pada PT. Trijaya Teknik Karawang Menggunakan Seven Tool dan Analisis Kaizen
}

\author{
Haula Alfadilah $^{1 *}$, Aulia Fashanah Hadining ${ }^{2}$, Hamdani ${ }^{3}$ \\ ${ }^{1,2,3}$ Program Studi Teknik Industri, Fakultas Teknik, Universitas Singaperbangsa Karawang \\ *Koresponden email: haulaalfadilah22@gmail.com
}

Diterima: 17 Desember 2021

Disetujui: 3 Februari 2022

\begin{abstract}
PT. Tri Jaya Teknik Karawang is a company that focuses primarily on manufacturing. One of the products owned by this company is Piece Pivot. In the production process, there are still defective products from Piece Pivot. The purpose of this research is to reduce the number of defective products on the Piece Pivot. The method used in this research is seven tools. The initial step of the research is the process of collecting data, after which the data processing and analysis is continued. From the seven tools that have been carried out, the most dominant product defect in the Piece Pivot product is the sloping hole. The problem points that have been analyzed lie in several aspects, and the aspect that most influences the Piece Pivot defect product is the method aspect, namely the production process using the discontinuous method and the lack of direction regarding the application of the applicable SOP. From the results of the Kaizen Five-M Checklist analysis, several suggestions for improvements can be made, namely increasing supervision on the implementation of SOPs, and updating production methods so that they can be more structured.
\end{abstract}

Keywords: defect, products, quality, tool, kaizen, seven tool

\begin{abstract}
Abstrak
PT. Tri Jaya Teknik Karawang adalah sebuah perusahaan yang fokus utamanya pada bidang manufaktur. Salah satu produk yang dimiliki oleh perusahaan ini adalah Piece Pivot. Dalam proses produksi, masih terdapat produk cacat dari Piece Pivot. Tujuan penelitian ini adalah menekan angka produk cacat pada Piece Pivot. Metode yang digunakan pada penelitian ini adalah seven tool. Seven tool merupakan alat dasar yang dapat digunakan dalam proses pengendalian kualitas yang terdiri dari Peta Kendali, Histogram, Check Sheet, Flowchart, Diagram scatter, Diagram Pareto, dan Diagram Fishbone. Langkah awal penelitian adalah proses pengumpulan data setelah itu dilanjut proses pengolahan dan analisis data. Dari ketujuh tools yang telah dilakukan didapatkan cacat produk yang paling dominan pada produk Piece Pivot adalah lubang yang miring. Titik permasalahan yang telah dianalisis terletak pada beberapa aspek dan aspek yang paling berpengaruh terhadap produk cacat Piece Pivot adalah aspek metode yaitu proses produksi yang menggunakan metode terputus-putus dan kurangnya pengarahan mengenai penerapan SOP yang berlaku. Dari hasil analisis Kaizen Five-M Checklist didapatkan beberapa usulan perbaikan yang dapat dilakukan yaitu dilakukan peningkatan pengawasan terhadap penerapan SOP, dan memperbarui metode produksi agar dapat lebih terstruktur.
\end{abstract}

Kata Kunci: cacat, produk, kualitas, alat, kaizen, seven tool

\section{Pendahuluan}

Di Indonesia bisnis berkembang dengan cukup pesat, sehingga menimbulkan kompetisi antar perusahaan yang semakin ketat. Untuk dapat bertahan di masa persaingan ini, perusahaan harus memiliki daya saing yang tinggi juga. Banyak strategi yang dapat dilakukan manajemen perusahaan untuk merespon persaingan tersebut seperti meningkatkan kualitas produk, berinovasi secara kontinu, hingga menekan biaya dalam proses produksinya (1). Indikator peningkatan mutu produk yang dimiliki perusahaan dapat dilihat dari kepuasan pelanggan. Perilaku pelanggan yang kuat dan melakukan pembelian atau penggunaan produk atau jasa secara berulang dapat menjadi tanda bahwa konsumen tersebut merasa puas pada perusahaan (2).

Setiap perusahaan dalam menjual produk atau jasanya memiliki tujuan akhir yang sama, yaitu memberikan kepuasan pada pelanggannya. Banyak aspek yang dapat membantu mencapai kepuasan pelanggan, salah satunya adalah kualitas produk yang baik. Selain pada kepuasan pelanggan kemampuan menghasilkan produk yang berkualitas dapat menjadi suatu keunggulan perusahaan dalam berkompetisi dengan pesaingnya untuk bertahan di era persaingan bisnis (3). Hal ini dikarenakan tingginya kualitas 
produk yang dimiliki adalah salah satu dari lima keunggulan kompetitif yang dapat dimanfaatkan untuk mengungguli pesaing (4).

Dalam upaya meningkatkan daya saing suatu produk, kualitas dapat menjadi salah satu faktor yang dapat membantu mencapai hal tersebut (5). Karena itu, pengendalian pada kualitas produk dirasa penting karena menjadi salah satu aspek dalam memenangkan posisi di era persaingan bisnis (6). Perusahaan yang mampu menerapkan pengendalian mutu, pada dasarnya akan mampu menghasilkan keuntungan lebih besar karena produk yang dihasilkan baik dan minim kerusakan. Dalam prosesnya, pengendalian kualitas mestinya mampu merumuskan pada tujuan yang terstruktur dan jelas sehingga dapat mencapai dan memberikan kepuasan pada pelanggan dalam menggunakan produk atau jasanya (7).

Salah satu alat yang cukup sering digunakan dalam proses pengendalian kualitas adalah seven tool. Seven tool adalah kumpulan beberapa alat yang sering kali digunakan oleh perusahaan atau organisasi dalam proses mengendalikan kualitas produk (5). Ref. (5) menjelaskan checksheet merupakan lembar data yang diperlukan untuk tujuan perekaman data jumlah produksi dan jumlah produk cacat, flow chart merupakan alat bantu untuk memvisualisasikan proses pembuatan produk secara bertahap dengan tujuan mempermudah proses analisis produk cacat melalui proses produksi, histogram digunakan sebagai alat penyaji data yang menunjukkan distribusi frekuensi, peta kendali merupakan sebuah peta yang dalam penggunaannya adalah untuk mempelajari perubahan suatu data dalam periode tertentu. Scatter diagram dirancang bertujuan untuk menunjukkan korelasi antara jumlah produk cacat dengan jumlah produk yang diproduksi. Diagram pareto yaitu untuk mengidentifikasi jenis cacat yang paling sering terjadi pada produk, dan yang terakhir yaitu Diagram fishbone merupakan diagram yang digunakan untuk mengidentifikasi berbagai sebab dari suatu masalah.

Penelitian yang dilakukan (8), metode seven tool digunakan untuk mengidentifikasi jenis cacat serta penyebab terjadinya cacat pada produksi amplang. Penelitian yang dilakukan (9), analisis seven tool digunakan untuk proses pengendalian kualitas dan menekan angka terjadinya cacat pada proses cutting bertujuan untuk menganalisis dengan seven tool dan kaizen untuk. Penelitian yang dilakukan (10), metode seven tool digunakan untuk mengendalikan kecacatan pada produksi botol plastik $60 \mathrm{ml}$. Penelitian yang dilakukan (11), penggunaan new seven tool digunakan untuk perbaikan kualitas dengan mengetahui penyebab cacat dan perbaikannya. Penelitian yang dilakukan (12), dilakukan untuk menerapkan alat bantu statistik dalam pengendalian kualitas dalam rangka mengendalikan tingkat kerusakan produk pada perusahaan. Adapun kebaharuan pada penelitian ini adalah penggunaan analisis Kaizen yang dipadukan dengan seven tool. Analisis Kaizen digunakan untuk mengidentifikasi penyebab terjadinya kerusakan berdasarkan aspek manusia, mesin, metode, material, tool, dan lingkungan. Ref. (13) dalam penelitiannya menjelaskan bahwa Kaizen merupakan perbaikan yang dilakukan dengan tujuan menghilangkan pemborosan, menghilangkan beban kerja berlebih dan selalu memperbaiki kualitas produk. Penggunaa seven tool sebagai alat identifikasi penyebab cacat dan Kaizen sebagai metode untuk memperbaiki kualitas produk diharapkan mampu meningkatkan kualitas produk pada Piece Pivot.

PT. Tri Jaya Teknik Karawang adalah sebuah perusahaan manufaktur yang fokus utamanya pada bidang machining, fabrikasi, serta stamping part (14). Perusahaan tersebut berada di kabupaten Karawang provinsi Jawa Barat. Produk yang di hasilkan antara lain konveyor gulung, kaki palet, tank minyak dan Piece Pivot. Pada saat produksi sering kali terjadi kendala yang dapat menghambat perusahaan dalam memenuhi permintaan konsumen, yaitu produk cacat. Dalam merespons permasalahan tersebut, maka perlunya dilakukan analisis untuk mengidentifikasi permasalahan yang terjadi. Selain itu analisis tersebut dilakukan untuk mengetahui penyebab terjadinya cacat serta cara untuk mengatasinya agar tidak lagi terjadi produk cacat (15). Produk tersebut diantaranya Piece Pivot karena merupakan produk yang paling banyak dan sering di produksi.

Sumber daya manusia di Departemen Quality Control (QC) pada PT Trijaya Teknik masih sangat terbatas, diperlukan metode pengendalian kualitas yang sederhana dan mudah di implementasikan. Untuk itu, pada penelitian ini dilakukan pengendalian kualitas yang diharapkan dapat mengurangi produk cacat pada Piece Pivot. Tujuan penelitian ini adalah untuk mengidentifikasi cacat yang terjadi dengan menggunakan Seven Tool dan Kaizen sebagai sebagai metode untuk memperbaiki kualitas produk.

\section{Metode Penelitian}

Metode penelitian dimaksudkan sebagai alur pada penelitian ini secara sistematis dari dimulainya penelitian hingga selesai. Adapun metodologi penelitian kali ini terlihat pada Gambar 1. 


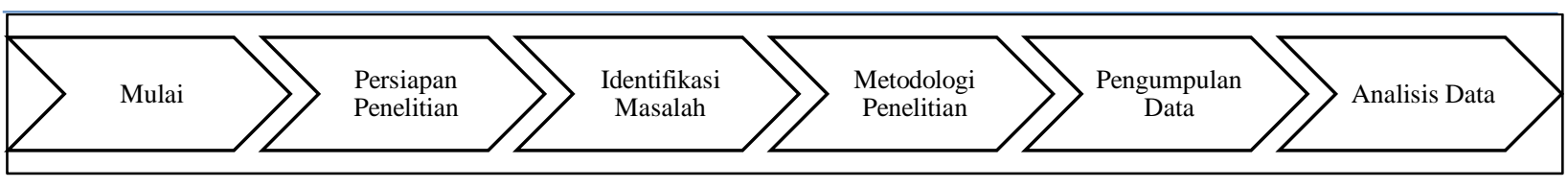

Gambar 1. Alur penelitian

Sumber: Data penelitian, 2021

Dari Gambar 1, tampak alur penelitian dari persiapan hingga analisis data, Tahap pertama pada penelitian ini dengan dimulainya penelitian, yaitu pada tanggal 22 Maret 2021. Tahap kedua, yaitu Persiapan penelitian dengan melakukan studi literatur dan studi lapangan untuk mempelajari korelasi antara teori dan keadaan lapangan. Tahap ketiga, yaitu identifikasi masalah yang dirumuskan berdasarkan permasalahan yang menjadi latar belakang pada objek penelitian. Masalah yang ditemukan adalah tingkat cacat yang terjadi pada Part PLG dapat menyebabkan inefisiensi proses produksi. Selanjutnya, tahap metode penelitian dilakukan dengan merumuskan alur dalam penelitian ini dimulai dari persiapan penelitian hingga analisis data.

Tahap selanjutnya, yaitu pengumpulan data yang dilakukan dengan tujuan mendapatkan informasi yang diperlukan sesuai dengan tujuan yang ingin dicapai. Data penelitian ini yaitu data umum perusahaan yang di dapatkan dari wawancara pada Kadept produksi PT. Trijaya Teknik Karawang, data proses pengendalian kualitas yang didapatkan dari observasi dan wawancara dengan Kadept QC PT. Trijaya Teknik Karawang. Sementara data jumlah kecacatan produk yang didapatkan dari admin produksi PT. Trijaya Teknik Karawang.

Setelah dilakukan pengumpulan data tahap selanjutnya yaitu analisis data. Penelitian ini adalah jenis penelitian deskriptif kuantitatif, dan dilakukan analisis dengan metode kuantitatif deskriptif. Analisis deskriptif kuantitatif digunakan untuk menganalisis tingkat cacat yang terjadi dengan menggunakan Seven tool. Ref (16) dalam penelitiannya menjelaskan seven tool merupakan alat atau teknik pengendalian kualitas yang mudah digunakan dalam setiap jenis usaha karena metode, persyaratan keterampilan, maksud dan mekanismenya sangat sederhana dan mudah dimengerti untuk setiap latar belakang pendidikan karyawan di dalam industri. Ref (5) menjelaskan checksheet merupakan lembar data yang diperlukan untuk tujuan perekaman data jumlah produksi dan jumlah produk cacat. Flow chart merupakan alat bantu untuk memvisualisasikan proses pembuatan produk secara bertahap dengan tujuan mempermudah proses analisis produk cacat melalui proses produksi. Histogram digunakan sebagai alat penyaji data yang menunjukkan distribusi frekuensi, Peta kendali merupakan sebuah peta yang dalam penggunaannya adalah untuk mempelajari perubahan suatu data dalam periode tertentu. Scatter Diagram dirancang bertujuan untuk menunjukkan korelasi antara jumlah produk cacat dengan jumlah produk yang diproduksi. Diagram pareto yaitu untuk mengidentifikasi jenis cacat yang paling sering terjadi pada produk, dan yang terakhir yaitu Diagram fishbone merupakan diagram untuk mengidentifikasi berbagai sebab dari suatu masalah.

Untuk analisis lanjutan dalam memperbaiki kualitas produk digunakan analisis Kaizen Five-M Checklist. Konsep Kaizen digunakan untuk menganalisis dan memberikan usulan perbaikan dari penyebab terjadinya cacat produk. Ref (17) menyatakan Kaizen memberikan perubahan yang sangat besar pada banyak perusahaan di Jepang. Kaizen berfokus pada perbaikan secara terus menerus dengan strategi yang diterapkan yaitu manajemen harus memuaskan pelanggan dan memenuhi kebutuhan pelanggan. dengan menggunakan seven tool sebagai alat mengidentifikasi penyebab cacat dan Kaizen sebagai metode untuk memperbaiki kualitas produk diharapkan mampu meningkatkan kualitas produk pada Piece Pivot.

\section{Hasil dan Pembahasan}

Sebagai upaya meminimalisir terjadinya kembalinya produk yang cacat, dilakukan analisis menggunakan Seven Tool yaitu (Checksheet, Flowchart, Histogram, Control Chart, Diagram Scatter, Diagram Pareto, Diagram Fishbone). Hasil yang didapatkan pada penelitian ini di tuliskan sebagai berikut: Checksheet

Check sheet merupakan lembar data yang diperlukan untuk tujuan perekaman data jumlah produksi dan jumlah produk cacat (5). Checksheet yang digunakan berupa data produk cacat yang didapatkan berdasarkan laporan NG bulanan PT. Trijaya Teknik Karawang seperti pada Tabel 2. 
Tabel 1. Hasil Checkseet produk cacat Piece Pivot

\begin{tabular}{|c|c|c|c|c|c|}
\hline \multirow{2}{*}{ Bulan } & \multirow{2}{*}{$\begin{array}{l}\text { Produksi } \\
\quad(p c s)\end{array}$} & \multicolumn{4}{|c|}{ Jenis Cacat (pcs) } \\
\hline & & Blank & Pierching 1 & Bending & Pierching 2 \\
\hline \multicolumn{6}{|c|}{2019} \\
\hline November & 10.800 & 30 & 78 & 54 & 21 \\
\hline Desember & 10.200 & 30 & 42 & 20 & 19 \\
\hline \multicolumn{6}{|c|}{2020} \\
\hline Januari & 15.000 & 28 & 40 & 39 & 24 \\
\hline Februari & 12.000 & 21 & 16 & 34 & 31 \\
\hline Maret & 9.000 & 27 & 35 & 22 & 20 \\
\hline Juli & 13.000 & 20 & 50 & 56 & 16 \\
\hline \multirow{2}{*}{ Bulan } & \multirow{2}{*}{$\begin{array}{l}\text { Produksi } \\
\quad(p c s)\end{array}$} & \multicolumn{4}{|c|}{ Jenis Cacat ( $p c s)$} \\
\hline & & Blank & Pierching 1 & Bending & Pierching 2 \\
\hline \multicolumn{6}{|c|}{2020} \\
\hline Agustus & 7.000 & 30 & 51 & 52 & 29 \\
\hline September & 6.000 & 29 & 22 & 32 & 31 \\
\hline November & 4.000 & 32 & 70 & 47 & 52 \\
\hline \multicolumn{6}{|c|}{2021} \\
\hline Januari & 11.000 & 32 & 28 & 28 & 32 \\
\hline Februari & 7.000 & 28 & 21 & 22 & 15 \\
\hline Maret & 7.000 & 30 & 39 & 40 & 20 \\
\hline Total & 112.000 & 337 & 492 & 446 & 310 \\
\hline
\end{tabular}

Sumber: PT. Trijaya Teknik Karawang (2021)

Berdasarkan hasil identifikasi yang dilakukan, jenis cacat didasarkan pada proses produksi yang dilalui dalam pembuatan Piece Pivot. Proses produksi Piece Pivot dilakukan secara bertahap, dimulai dari proses Blank, Pierching 1, Bending, dan Pierching 2. Kategori cacat diberikan nama berdasarkan proses tempat terjadinya cacat. Standarisasi maksimal produk cacat pada PT. Trijaya Teknik Karawang yaitu 5\% dari jumlah produk yang di produksi. Dari Tabel 1 diketahui total cacat yang dihasilkan selama 12 kali produksi adalah 1.585 pcs atau $1,4 \%$ dari jumlah produk yang di produksi. Data dari check sheet ini digunakan untuk proses pembuatan tools Histogram, Diagram Scatter, Diagram Pareto, dan Control Chart. Flowchart

Tools yang kedua, yaitu diagram alir atau Flow Chart merupakan alat bantu untuk memvisualisasikan proses pembuatan produk secara bertahap dengan tujuan mempermudah proses analisis produk cacat melalui proses produksi (5). Dari hasil observasi dengan Kadept produksi didapatkan Flowchart proses pembuatan produk Piece Pivot seperti pada Gambar 2. 


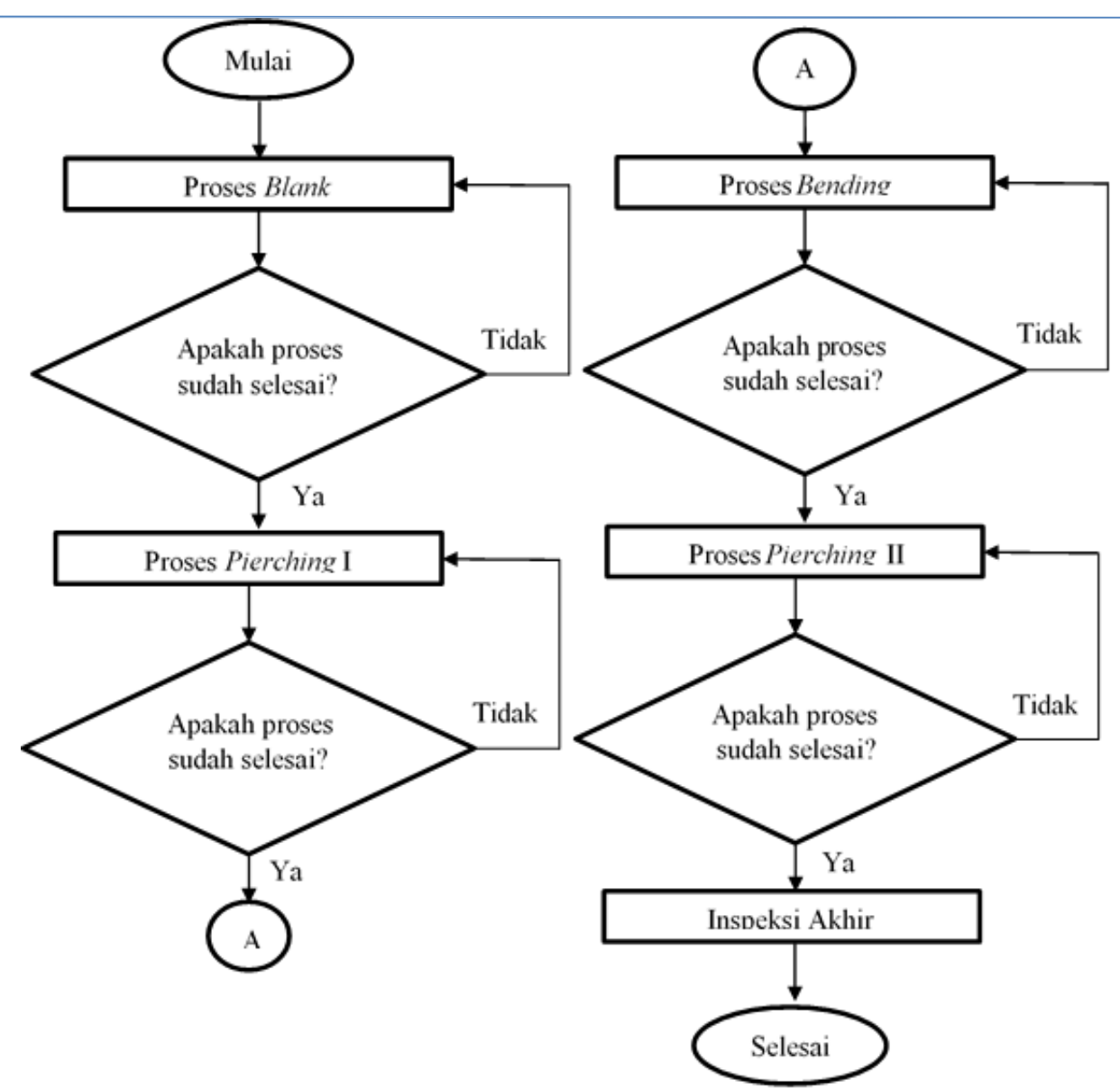

Gambar 2. Flowchart pembuatan Piece Pivot

Sumber: PT. Trijaya Teknik Karawang (2021)

Flowchart sudah di implementasikan dalam pengendalian kualitas pada proses produksi Trijaya Teknik dengan tujuan mempermudah dalam memvisualisasikan proses pembuatan produk.

Histogram

Histogram digunakan sebagai alat penyaji data yang menunjukkan distribusi frekuensi (5). Jenis cacat yang telah dikategorikan pada check sheet kemudian direkapitulasi dan disajikan ke dalam bentuk Histogram. Histogram produk cacat produk Piece Pivot terlihat pada Gambar 3.

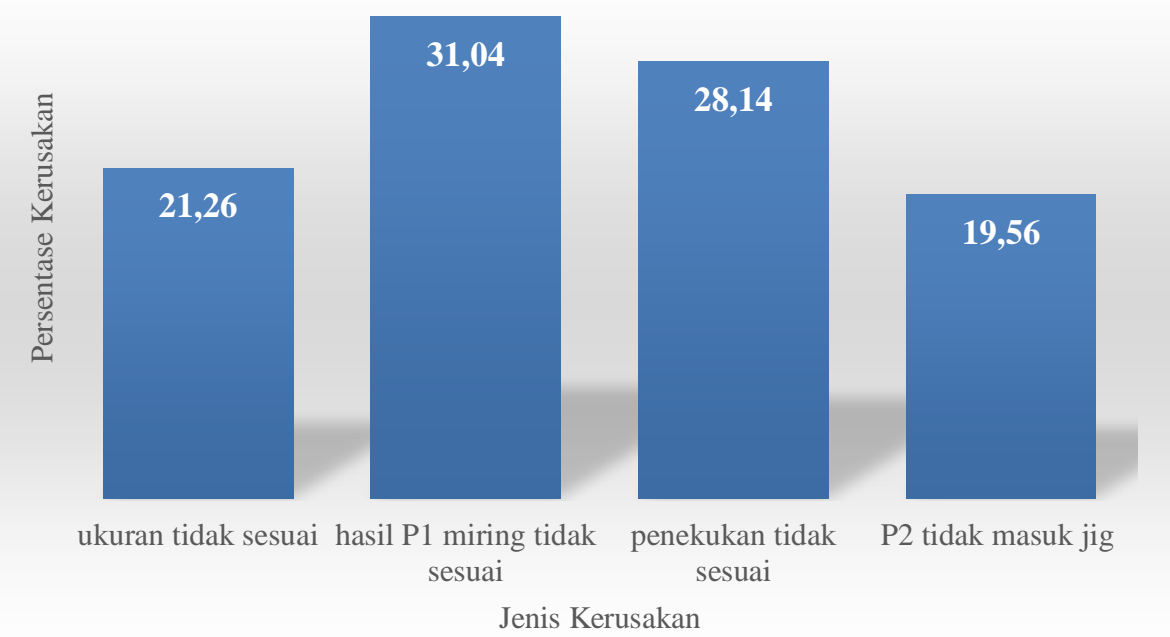

Gambar 3. Histogram produk cacat Piece Pivot Sumber: Data penelitian (2021) 
Dari Histogram menunjukkan jenis produk cacat yang paling dominan terdapat pada hasil Pierching 1 yaitu kemiringan yang tidak sesuai. Jenis produk cacat yang paling dominan akan menjadi prioritas dalam proses pengendalian kualitas.

\section{Control Chart}

Control Chart atau peta kendali dalam analisis ini pun menjadi alat analisis lanjutan guna mengenali penyebab masalah dan cara pemecahan masalah dalam pengendalian kualitas di PT Trijaya Teknik Karawang. Peta kendali merupakan sebuah peta yang dalam penggunaannya adalah untuk mempelajari perubahan suatu data dalam periode tertentu (5). Peta kendali yang digunakan dalam pengendalian kualitas Piece Pivot ini adalah peta P karena menggunakan $100 \%$ inspeksi (18). Control Chart dimuat dalam bentuk grafik peta untuk mengetahui kondisi data seperti pada Gambar 4.

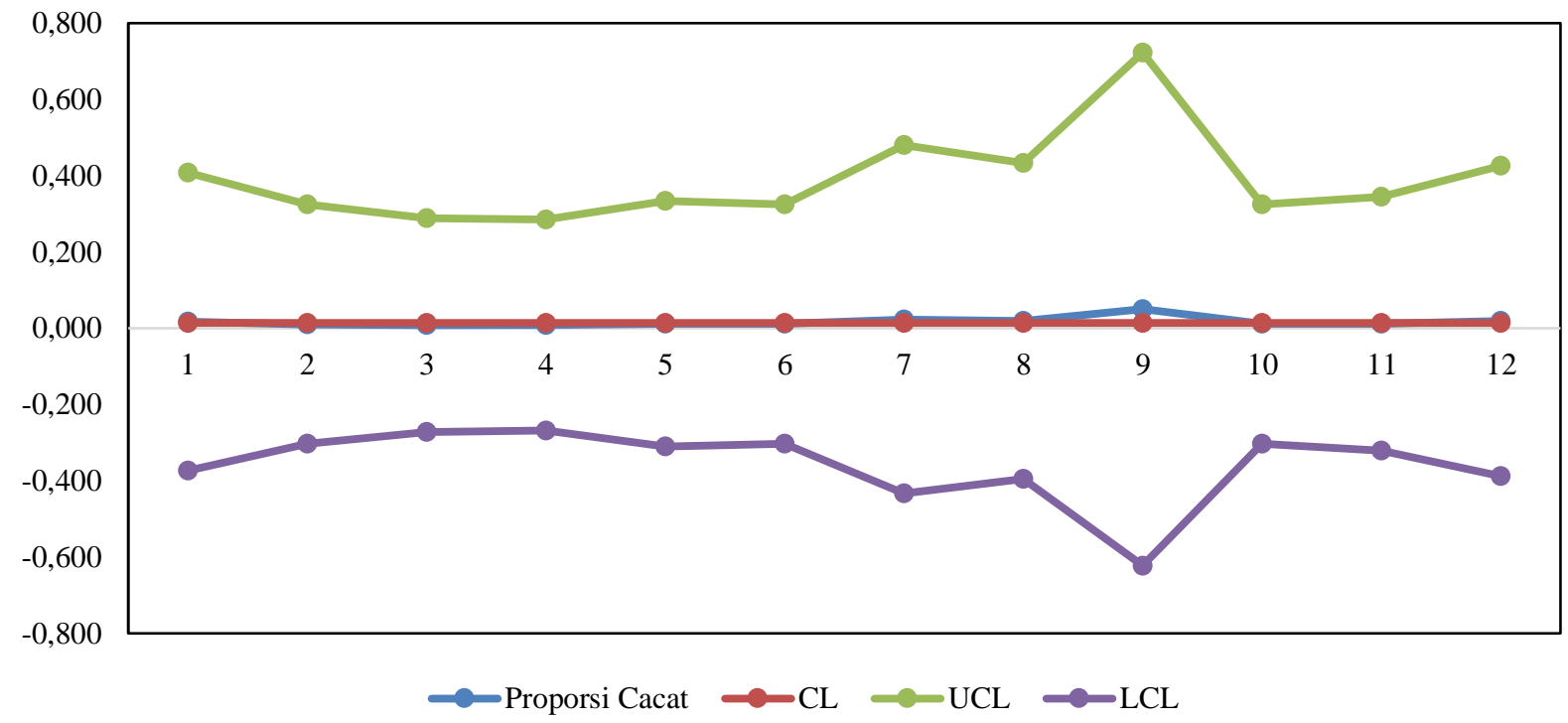

Gambar 4. Control Chart Piece Pivot

Sumber: Data penelitian (2021)

Berdasarkan hasil pada Gambar 4 diketahui bahwa data tidak ada yang keluar dari batas kendali. Hal ini berarti pengendalian kualitas yang dilakukan selama periode satu tahun pada produksi Piece Pivot masih dalam batas kendali yang ditentukan. Namun untuk mendapatkan kualitas yang lebih baik pengendalian kualitas masih harus tetap dilakukan agar didapatkan zero defect.

Scatter Diagram

Scatter Diagram dirancang bertujuan untuk menunjukkan korelasi antara jumlah produk cacat dengan jumlah produk yang diproduksi (5). Scatter diagram diawali dengan mengidentifikasikan persentase cacat tiap sampel. persentase cacat berdasarkan produksi dibuatkan dalam bentuk scatter diagram dengan hubungan dari dua variabel yaitu hubungan antara jumlah produksi dan jumlah produk cacat pada Piece Pivot. Diagram scatter dari jumlah produksi dan jumlah produk cacat yaitu terlihat pada Gambar 5.

Berdasarkan diagram Scatter pada Gambar 5 diketahui bahwa sebaran hubungan antara jumlah produksi dan jumlah produk cacat tidak membentuk korelasi. Hal ini menunjukkan bahwa jumlah produk cacat masih dapat diatasi dan tidak memiliki pengaruh yang cukup besar terhadap jumlah produksi. Namun, pengendalian kualitas masih harus tetap dilakukan untuk mendapatkan Zero Defect. 


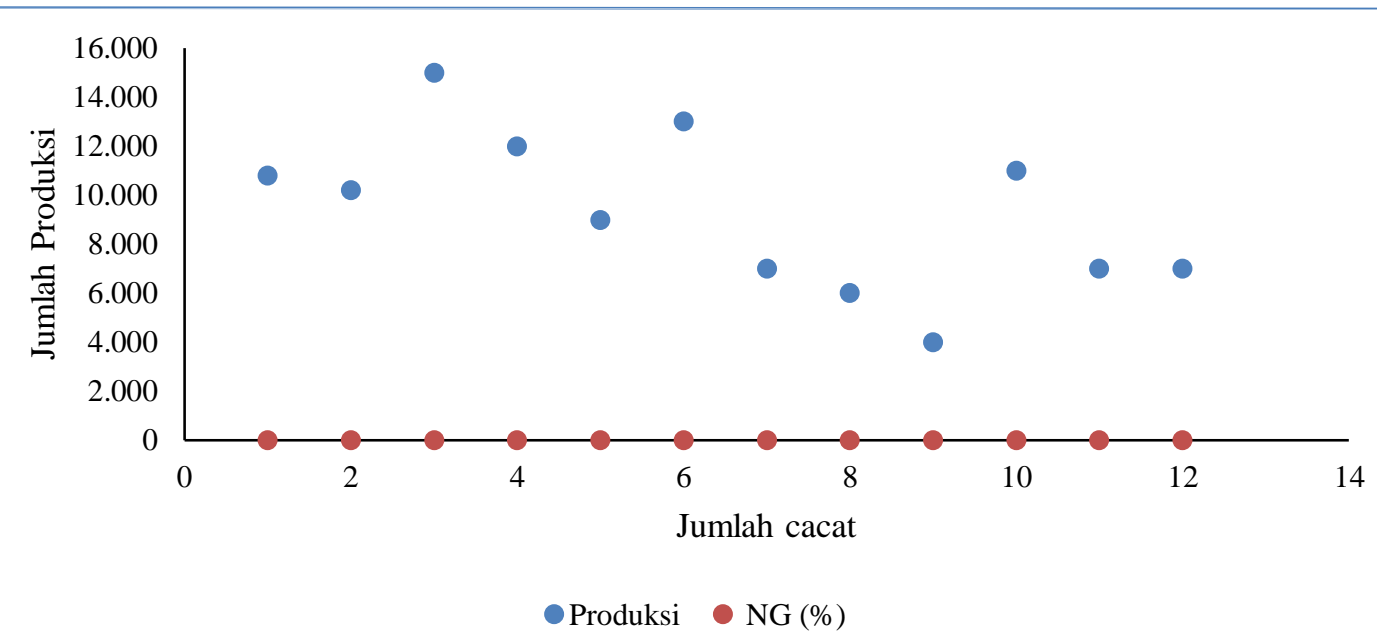

Gambar 5. Scatter diagram

Sumber: Data penelitian (2021)

\section{Diagram Pareto}

Tahap selanjutnya dalam mengidentifikasi produk cacat menggunakan seven tool adalah membuat diagram Pareto. Penggunaan diagram Pareto yaitu untuk mengidentifikasi jenis cacat yang paling sering terjadi pada produk (5). Hal ini bertujuan untuk menentukan prioritas perbaikan berdasarkan jenis cacat yang paling sering terjadi. Langkah pertama dalam membuat diagram Pareto adalah dengan menghitung persen kumulatif setiap jenis cacat yang ada. Persentase kumulatif tiap jenis cacat yang terjadi yaitu hasil P1 miring sebesar $31 \%$, penekukan tidak sesuai sebesar 59\%, ukuran tidak sesuai sebesar $80 \%$, dan Pierching 2 tidak masuk jika sebesar 100\%. Kemudian dari hasil tersebut dimuat dalam bentuk diagram Pareto seperti pada Gambar 6.

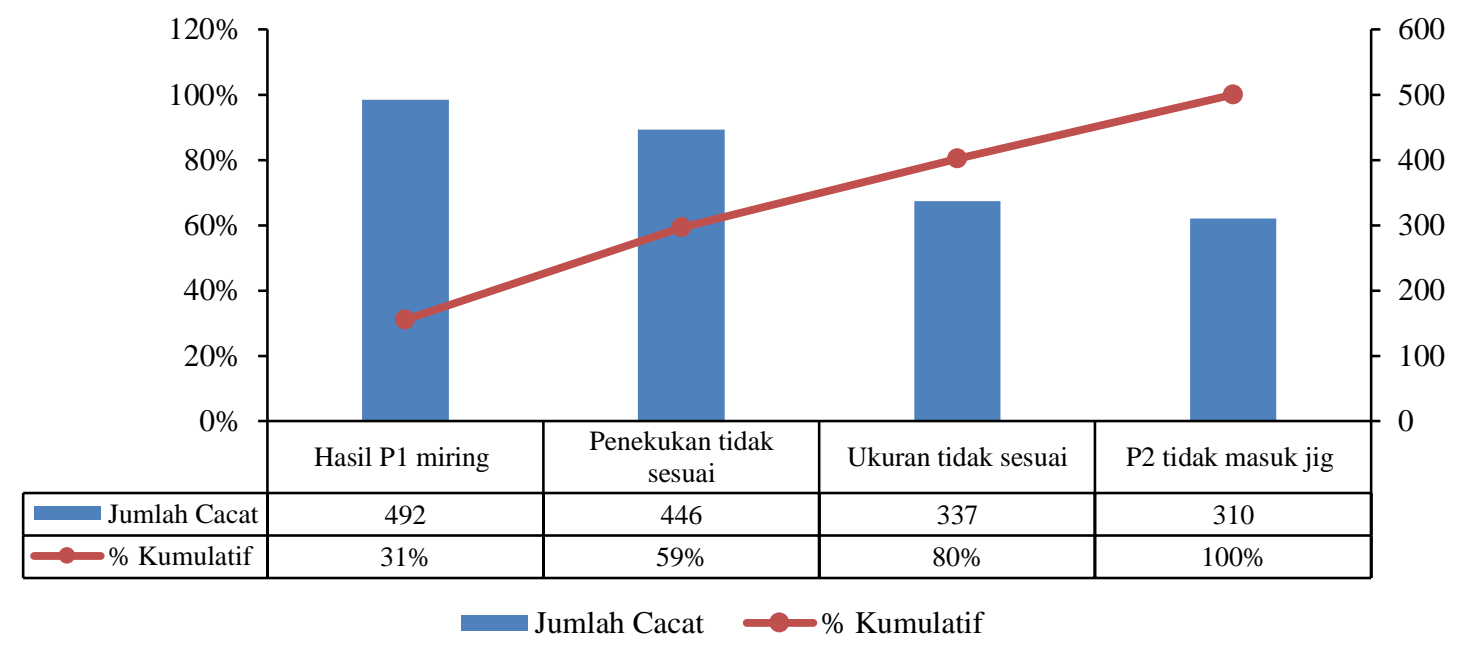

Gambar 6. Diagram Pareto

Sumber: Data penelitian (2021)

Berdasarkan hasil yang didapatkan pada diagram Pareto di atas, dapat diketahui jenis cacat yang paling sering terjadi yaitu pada hasil Piercing 1 miring. Oleh karena itu, pada tahap selanjutnya yaitu perbaikan, jenis cacat Piercing 1 miring akan menjadi prioritas untuk dianalisis usulan perbaikannya menggunakan Kaizen Five-M Checklist.

\section{Fishbone Diagram}

Puncak analisis lanjutan yang dilakukan untuk mengetahui penyebab kecacatan yaitu dengan penyusunan diagram sebab akibat. Diagram Fishbone merupakan diagram yang digunakan untuk mengidentifikasi berbagai sebab dari suatu masalah (5). Dari hasil yang didapatkan pada diagram Pareto diketahui bahwa jenis cacat yang paling sering terjadi adalah hasil Pierching 1 miring. Oleh karena itu pada analisis diagram Fishbone dilakukan hanya pada jenis cacat tersebut. Informasi data untuk diagram Fishbone diperoleh dari hasil observasi dan wawancara dengan Kadept QC PT. Trijaya Teknik Karawang. 
Hal ini bertujuan untuk mengetahui penyebab terjadinya cacat Hasil Pierching 1 miring seperti pada Gambar 7.

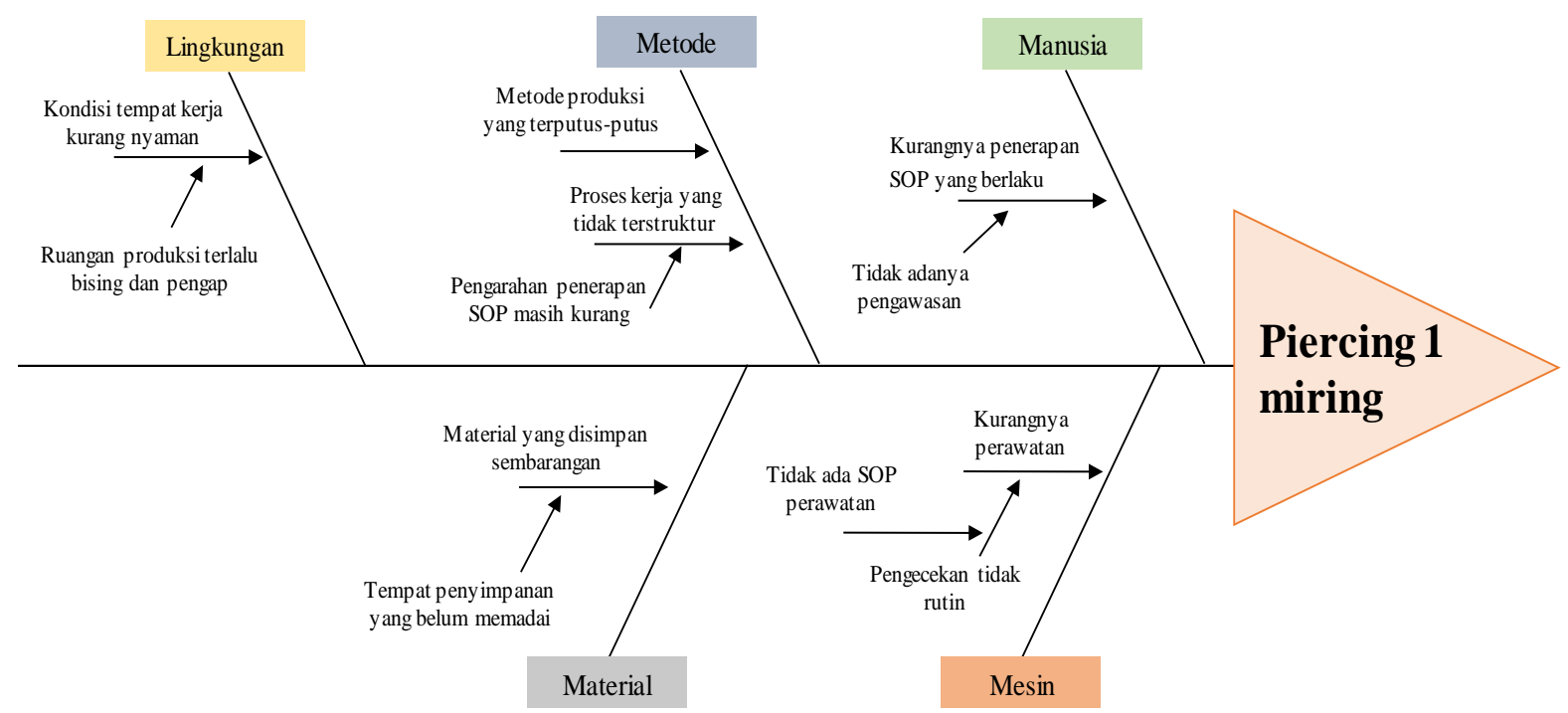

Gambar 7. Diagram Fishbone Piece Pivot Sumber: Data penelitian (2021)

Berdasarkan diagram Fishbone pada Gambar 7 dapat diketahui penyebab terjadinya cacat Pierching 1 miring terdiri dari berbagai aspek seperti manusia, mesin, metode, material dan lingkungan. Diagram Fishbone sudah diterapkan oleh PT. Trijaya Teknik sebagai alat untuk mengidentifikasi kecacatan produk. Analisis Kaizen Five-M Checklist

Setelah diidentifikasi cacat yang terjadi pada proses produksi Piece Pivot hingga diketahui penyebab terjadinya cacat. Maka selanjutnya dilakukan analisis lanjutan dalam upaya menekan angka terjadinya cacat. Analisis ini menggunakan metode Kaizen Five-M Checklist dengan hasil seperti pada Tabel 6.

Tabel 2. Hasil analisis Kaizen Five-M checklist

\begin{tabular}{|c|c|c|c|}
\hline No & Faktor & Masalah & Usulan Perbaikan \\
\hline 1. & Manusia & $\begin{array}{l}\text { Proses kerja yang tidak teratur } \\
\text { karena kurangnya penerapan SOP } \\
\text { yang ada. }\end{array}$ & $\begin{array}{l}\text { - Peningkatan Pengawasan oleh bagian } \\
\text { terkait untuk penerapan SOP oleh } \\
\text { operator }\end{array}$ \\
\hline 2. & Mesin & $\begin{array}{l}\text { Kurangnya perawatan mesin karena } \\
\text { proses perawatan yang sulit karena } \\
\text { penggunaan mesin impor. }\end{array}$ & $\begin{array}{l}\text { - Mengadakan perawatan berkala kecil- } \\
\text { kecilan secara kontinyu } \\
\text { - Melakukan pengawasan dan kalibrasi per } \\
\text { periode tertentu }\end{array}$ \\
\hline 3. & Material & $\begin{array}{l}\text { Bahan baku yang berkarat karena } \\
\text { disimpan bukan di tempat khusus }\end{array}$ & $\begin{array}{lll}\text { - Pengadaan tempat khusus } & \text { untuk } \\
\text { penyimpanan bahan baku } & \text { untuk } \\
\text { menghindari bahan baku berkarat. } & \end{array}$ \\
\hline 4. & Metode & $\begin{array}{l}\text { - Metode produksi yang terputus- } \\
\text { putus menyebabkan produk } \\
\text { mengalami kerusakan saat } \\
\text { menunggu proses lain } \\
\text { - } \text { Kurangnya pengawasan dan } \\
\text { pengarahan SOP pada pegawai }\end{array}$ & $\begin{array}{l}\text { - Memperbarui metode produksi agar dapat } \\
\text { lebih terstruktur } \\
\text { - Membuat sistematika dan panduan kerja } \\
\text { yang sesuai pada proses produksi Piece } \\
\text { Pivot } \\
\text { - Pengarahan kerja setiap awal hari sebelum } \\
\text { melakukan pekerjaan }\end{array}$ \\
\hline 5. & Environment & $\begin{array}{l}\text { - Tempat kerja yang terlalu bising } \\
\text { karena bersebelahan dengan } \\
\text { proses lain } \\
\text { - Tata letak perusahaan belum } \\
\text { optimal }\end{array}$ & $\begin{array}{l}\text { - Menata ulang tata letak produksi tiap } \\
\text { departemen } \\
\text { - Memberikan batasan yang jelas tiap } \\
\text { departemen }\end{array}$ \\
\hline
\end{tabular}




\section{Kesimpulan}

Dari ketujuh tool yang telah dibuat terdapat 3 tool yang sudah diimplementasikan sebagai alat pengendalian kualitas pada PT. Trijaya Teknik yaitu tool check sheet, Control Chart dan Histogram karena merupakan tool yang sederhana dan mudah di implementasikan. Berdasarkan hasil yang didapatkan pada Diagram Fishbone penyebab cacat terdapat pada beberapa aspek yaitu aspek metode, material, mesin, manusia dan lingkungan. Dari beberapa aspek pengaruh kecacatan, aspek yang paling dominan terletak pada aspek metode yaitu proses produksi yang menggunakan metode terputus-putus dan kurangnya pengarahan mengenai penerapan SOP yang berlaku. Dari hasil analisis Kaizen Five-M checklist didapatkan beberapa usulan perbaikan yang dapat dilakukan yaitu dilakukan peningkatan pengawasan terhadap penerapan SOP, membuat sistematika dan panduan kerja yang sesuai pada proses produksi Piece Pivot dan memperbarui metode produksi agar dapat lebih terstruktur.

\section{Referensi}

1. Nurkholiq A, Saryono O, Setiawan I. Analisis Pengendalian Kualitas (Quality Control) Dalam Meningkatkan Kualitas Produk. J Ekonologi. 2019;6(2):393-9.

2. Afnina A, Hastuti Y. Pengaruh Kualitas Produk Terhadap Kepuasan Pelanggan. J Samudra Ekon Dan Bisnis. 2018;9(1):21-30.

3. Rahayu P, Bernik M. Peningkatan Pengendalian Kualitas Produk Roti Dengan Metode Six Sigma Menggunakan New \& Old 7 Tools. J Bisnis Kewirausahaan. 2020;16(2):1-9.

4. Putri Rl. Peningkatan Kualitas Produk Melalui Penerapan Prosedur Dan Sistem Produksi : Studi Pada UD Wijaya Kusuma Kota Blitar. 2016 :813-28.

5. Idris I, Sari Ra, Wulandari, Pengendalian Kualitas Tempe Dengan Metode Seven Tools. J Teknovasi. $2018 ; 03(1): 66-80$.

6. Lestari Fa, Purwatmini N. Pengendalian Kualitas Produk Tekstil Menggunakan Metoda Dmaic. J Ecodemica J Ekon Manajemen, Dan Bisnis. 2021;5(1):79-85.

7. Elmas Msh. Pengendalian Kualitas Dengan Menggunakan Metode Statistical Quality Control (Sqc) Untuk Meminimumkan Produk Gagal Pada Toko Roti Barokah Bakery. J Penelit Ilmu Ekon. 2017;7(1):15-22.

8. Hairiyah N, Raden Rizki Amalia, Nuryati. Pengendalian Kualitas Amplang Menggunakan Seven Tools Di Ud. Kelompok Melati. J Agrointek. 2020;14(2):249-57.

9. Hendrawan Aa, Yustina, Pailan. Integrasi Penerapan Kaizen Dan Seven Tools Di PT. Gunawan. J Tekmapro. 2015;1-6.

10. Rofieq M, Septiari R. Penerapan Seven Tools Dalam Pengendalian Kualitas Botol Plastik Kemasan 60 Ml M. J Ind View. 2021;03(1):23-34.

11. Zakariya Y, Mu'tamar Mff, Hidayat K. Pengendalian Mutu Produk Air Minum Kemasan Menggunakan New Seven Tools ( Studi Kasus Di PT. Dea ). J Rekayasa. 2020;13(2):97-102.

12. Ratnadi, Suprianto E. Pengendalian Kualitas Produksi Menggunakan Alat Bantu Statistik (Seven Tools) Dalam Upaya Menekan Tingkat Kerusakan Produk. J Indept. 2016;6(2):10-8.

13. Fatkhurrohman A, Subawa. Penerapan Kaizen Dalam Meningkatkan Efisiensi Dan Kualitas Produk Pada Bagian Banbury PT. Bridgestone Tire Indonesia. J Adm Kant. 2016;4(1):14-31.

14. Adiyanto A, Herwanto D. Tinjauan Kapasitas Persediaan Produk Fuji Seat Pt . Tri Jaya Teknik Karawang. J Media Tek Dan Sist Ind. 2021;5(1):33-40.

15. Ulkhaq Mm, Pramono Snw, Halim R. Aplikasi Seven Tools Untuk Mengurangi Cacat Produk Pada Mesin Communite Di PT. Masscom Graphy, Semarang. J Pasti. 2017;11(3):220-30.

16. Subadi Sb Widjaja; Sab. The Implementation Of Seven Quality Management Tools : Experiences From Three Enterprises In East Java. Ubaya Int Annu Symp Manag. 2016;

17. Tri D, Rakhmanita A, Anggraini A. Implementasi Kaizen Dalam Meningkatkan Kinerja Pada Perusahaan Manufaktur di Tangerang. J Ecodemica J Ekon Manajemen, Dan Bisnis. 2019;3(2):198206.

18. Wibowo H, Sulastri, Arifudin A. Mengidentifikasi Kerusakan Pada Produk Batang Kawat Pt. Krakatau Steel (Persero) Tbk. In: Seminar Nasional Teknik Industri [Snti2017]. 2017. P. $13-4$. 